\title{
Lesions in the cerebral hemispheres after blunt head injury
}

\author{
SABINA J. STRICH \\ From the Department of Neuropathology, Institute of Psychiatry, London
}

Though this paper is limited to lesions in the cerebral hemispheres after non-penetrating head injury, they are unlikely to be confined to the hemispheres, or to the brainstem for that matter. No attempt is made to deal with all the types of lesion which may occur, in particular those due to systemic factors, such.as fat embolism or anoxia and complications such as meningitis or epilepsy, are omitted. For further information the reader is referred to Tomlinson (1964) and Strich (1969). Although some lesions due to head injury can be seen with the naked eye, many important ones can be seen only with the microscope. Different lesions will be described under separate headings, but often occur in various combinations within the same brain.

\section{Contusions and Lacerations}

Apart from subarachnoid haemorrhage, contusions are probably the most common macroscopic findings. They are areas of superficial damage consisting of streaks or groups of punctate haemorrhages accompanied by variable amounts of necrosis, and wedge-shaped areas of necrosis without haemorrhage also occur (Fig. 1). Like other destructive lesions contusions are surrounded by a zone of oedema (Fig. 1). Contusions are found under fracture lines and under the site of impact, particularly if the head was struck by a small, fast-moving object such as a cricket ball rather than a large one such as a brick wall. Most contusions, however, are found not near the site of the impact but on the undersurfaces of the frontal and temporal lobes and the sides and tips of the temporal lobes. Theseso-called 'contre-coup' contusions tend to occur in the same regions of the brain no matter where the blow. The details of the distribution vary. Contusions are often more extensive on the side oppositel the one which received the blow. The mechanism of production of 'contre-coup' contusions has puzzled pathotogists for centuries. Several authors (Gross, 19\$8; Sellier and Unterharnscheidt, 1963) hold that they are due to the collapse of bubbles formed at e site of negative intracranial pressure which tends to develop at a point diametrically opposite site of impact. There is, however, considerable doubt amongst physicists (Holbourn, 1948; Goldsmith, 1966) that sufficient negative press we to cause cavitation ever develops in the ordinary run of head injuries. Another difficulty is that, unless there are overlying fractures, contusions 迎e rarely seen in the occipital lobes or the cerebelluth after frontal blows, nor are they seen on convexities of the hemispheres.

The theory that contusions are rotational injuries (Holbourn, 1943 and 1945) fits the fasts better. Brain substance, like other fluids, is higk

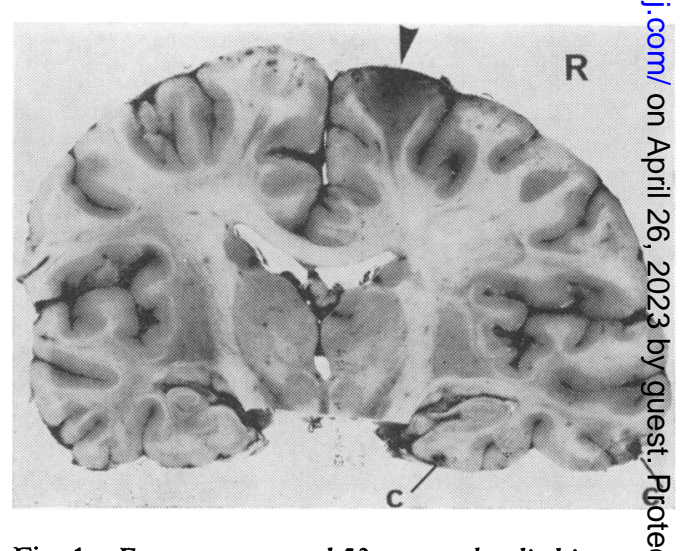

Fig. 1 From a man aged 53 years who died in coma seven days after a road accident. Fractures of the $\mathbb{Q}$ vault of the skull over the sagittal sinus passed into the right frontal region. Coronal section showing a wedge-shaped area of necrosis (arrow) on the right $\delta$ and a few small contusions (c). The right hemispherezis swollen. $\mathbf{R}=$ right. 
incompressible, this means that the brain cannot readily change in volume, it cannot draw away from the skull. or lag behind when the head moves. Changes in brain volume due to displacement of blood or of cerebrospinal fluid take place too slowly to matter in this context. The brain is, however, easily changed in shape and distorted and is likely to undergo swirling movements, particularly when there is rotation of the head (Holbourn, 1945). Where the brain glides over a smooth surface there may be subarachnoid haemorrhage due to displacement of the brain relative to the pia arachnoid and consequent tearing of blood vessels. But where the skull is uneven and is closely moulded to the convolutions, as in the floor of the anterior and middle fossae or around the sphenoidal ridge, surface damage occurs when the brain rotates.

Contusions heal in a few weeks after which time their age cannot be determined. The necrotic tissue is removed and the floor of the defect is covered by a glial or, occasionally, a thin collagenous scar. The end result is the characteristic shallow, often slightly yellow, defect running along the crests of gyri. In this, the scars differ from those left after necrosis due to small vascular lesions which are classically found at the bottom of sulci. The cortex at the edge of healed contusions is often gliosed and may contain calcified neurons. Healed contusions were an incidental finding in $2.5 \%$ of 2,000 consecutive necropsies reported by Welte (1948).

In a laceration the surface of the brain and the

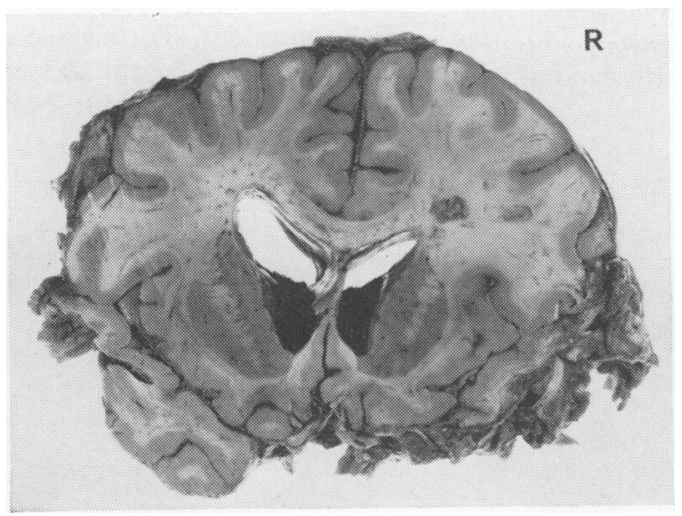

Fig. 2 From a man aged 55 years who had a large right-sided subdural haematoma evacuated seven hours after a motorcycle accident. Marked brain swelling postoperatively. Survival in a state of 'akinetic mutism' for three months. Coronal section shows that much of the right temporal lobe has disappeared (old laceration), the ventricles are dilated due to atrophy of white matter, and there are cysts in the white matter on the right. Microscopically there was evidence of previous severe, widespread cerebral oedema (Fig. 3). Healed brainstem haemorrhages were also present. $R=$ right. overlying leptomeninges are torn. This constitutes a more serious degree of brain damage than that due to contusions partly because it entails a more extensive loss of brain substance (Fig. 2). Lacerations leave a collagenous scar which may be attached to the dura, especially if this has also been torn. Such lesions are more likely to be epileptogenic than simple contusions. In the acute stage lacerations are surrounded by a larger zone of oedema than contusions and this may turn the damaged lobe into a significant space-occupying lesion. Oozing from injured blood vessels will lead to the accumulation of subarachnoid blood, or worse, to the formation of a subdural haematoma with all its complications.

\section{Cerebral Oedema}

Current work on cerebral oedema surrounding destructive lesions suggests that the leak of fluid occurs from damaged vessels in the actual lesion and that it seeps from there, extracellularly, into the surrounding white matter whose vascular permeability is not in itself abnormal (Klatzo, 1967). This has been demonstrated in experimentally produced necrotic brain lesions. A fluorescent dye which does not penetrate the normal blood-brain barrier is injected intravenously at the time of making the lesion. Some hours later, and shortly before killing the animal, a second dye fluorescing with a different colour is injected and the progress of the two substances can be visualized. The spread of oedema fluid is promoted by a high blood pressure (Klatzo, 1967).

Severe oedema of a hemisphere frequently occurs after the evacuation of an intracranial haematoma. This oedema does not respond well to the usual treatments and is a serious complication. Its pathogenesis is not understood. Swelling of the brain is not necessarily due to oedema fluid. It can be due to vascular engorgement which can be severe enough to increase the brain volume significantly and therefore to raise the intracranial pressure. This congestion can be minimized by providing a clear airway and good ventilation or even by hyperventilation of the lungs.

The accumulation of fluid in the white matter in cerebral oedema is accompanied by histological changes which can be seen with the light microscope. The astrocytes react quickly, that is, within hours in the experimental situation (Klatzo, Piraux, and Laskowski, 1958). Their nuclei enlarge and the cytoplasm, which is normally not visible, swells to become a homogeneous, eosiniphilic mass. These are the 'plump', 'swollen', 'reactive', or 'gemistocytic' astrocytes (Fig. 3). Silver impregnation shows that their processes also swell. The oedematous white matter looks pale in stained sections; the myelin sheaths are pushed apart and may look irregular or beaded. The astrocytes remain prominent for a long time (Fig. 
3). When the oedema resolves there is atrophy of the white matter and myelin actually disappears (Fig. 4) without the formation of the usual sudanophilic breakdown products. At the same time an astrocytic fibrous gliosis develops which may be very dense and is seen with stains to show

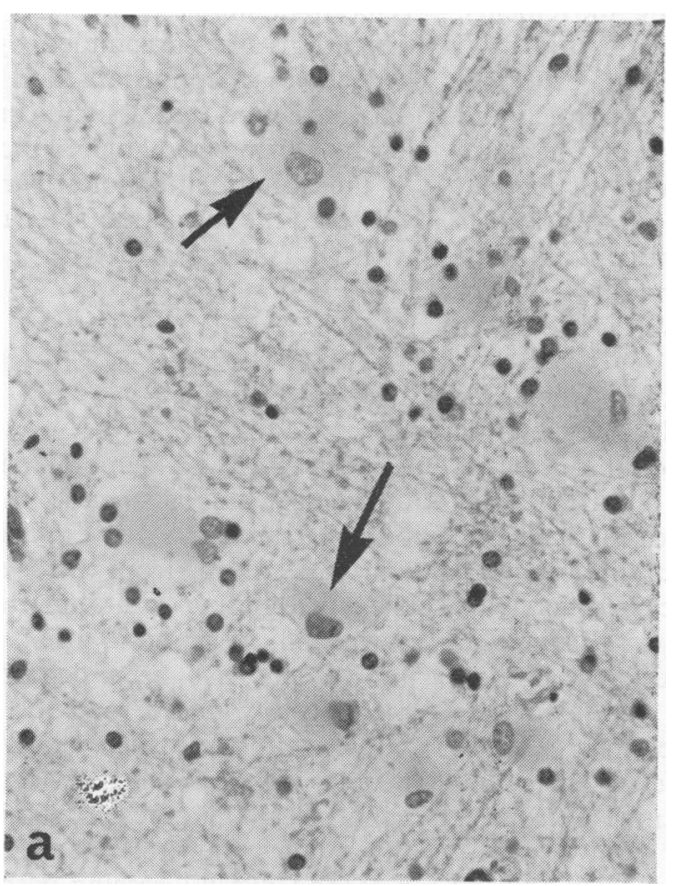

Fig. 3 Section of white matter from the brain seen in Figures 2 and 4. There are large numbers of plump, swollen astrocytes (arrows to some). Myelinated nerve fibres are sparse, but look normal. No fat granule cells. The appearances are typical of longstanding or resolved oedema. Survival time three months. Haematoxylin and eosin. $\times 300$.

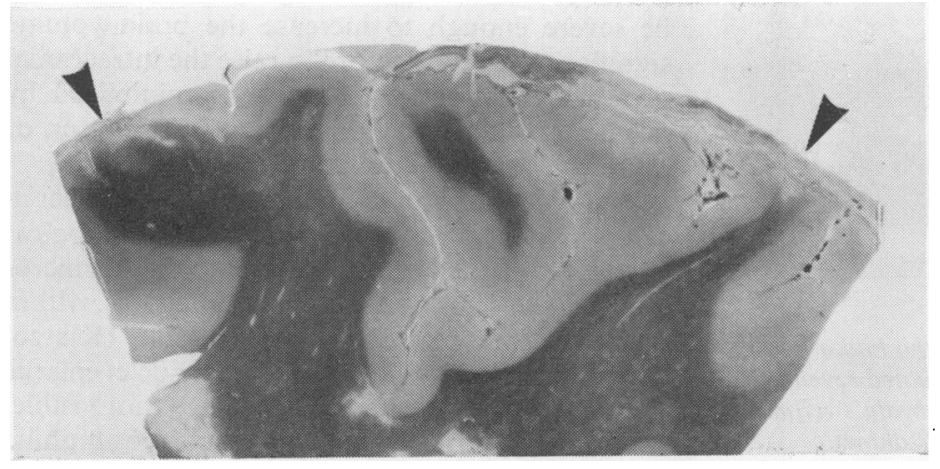

Fig. 4 Section of cortex and white matter from the brain seen in Figure 2. Myelin staining is pale and blotchy. Healed contusions at arrows (cf. Fig. 3). Myelin stain $\times 1 \cdot 7$. glial fibrils (Mallory's phosphotengstic haematoxylin, Holzer).

\section{Ischaemic Necrosis}

Areas of complete or partial tissue necrosis duह

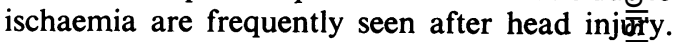
They may consist of small infarcts at the botrom of sulci or they may involve part or the whole the territory supplied by one of the major cerebral arteries. The cause of these vascular lesion $\overrightarrow{0}$ is unknown, but spasm due to distortion or strecthing of blood vessels or to direct damage of the vessel by bone fragments, etc, must be considered. Ischaemia at the boundary zones between jacent arterial territories because of systefflic hypotension (Adams, Brierley, Connor, and Trêtp 1966 ) is also an important factor.

\section{Central Haemorrhages}

Haemorrhages are a common macroscōic feature of head injury but frequently microscoigic ones are also present. Haemorrhages are usuâbly multiple and may occur anywhere but they haye some favourite sites, for instance, the coreus callosum (Lindenberg, Fisher, Durlacher, Lovtt, and Freytag, 1955), usually on its undersurfe्dce and to one side of the midline (Fig. 5), or the subcortical white matter. It is generally agreed that such haemorrhages and some of those in $\overrightarrow{\mathbb{Q}}$ e brainstem are of traumatic origin, that is, that they are due to tearing of blood vessels at the time of the accident. Torn vessels have in fact been demonstrated in serial sections in cases of he्ad injury (Krauland, 1950; Mayer, 1967). During

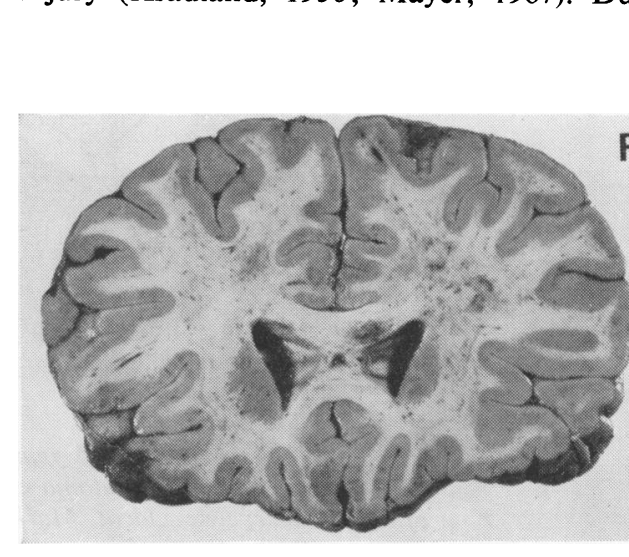

Fig. 5 From a man aged 25 years involved in a road accident and surviving in coma for five weeks. Coronal section of brain showing a haemorrhage in one sideø $f$ the corpus callosum and another in the parasagittal white matter on the right $(\mathrm{R})$. There was severe degeneration of the white matter microscopically (ses Fig. 6). 


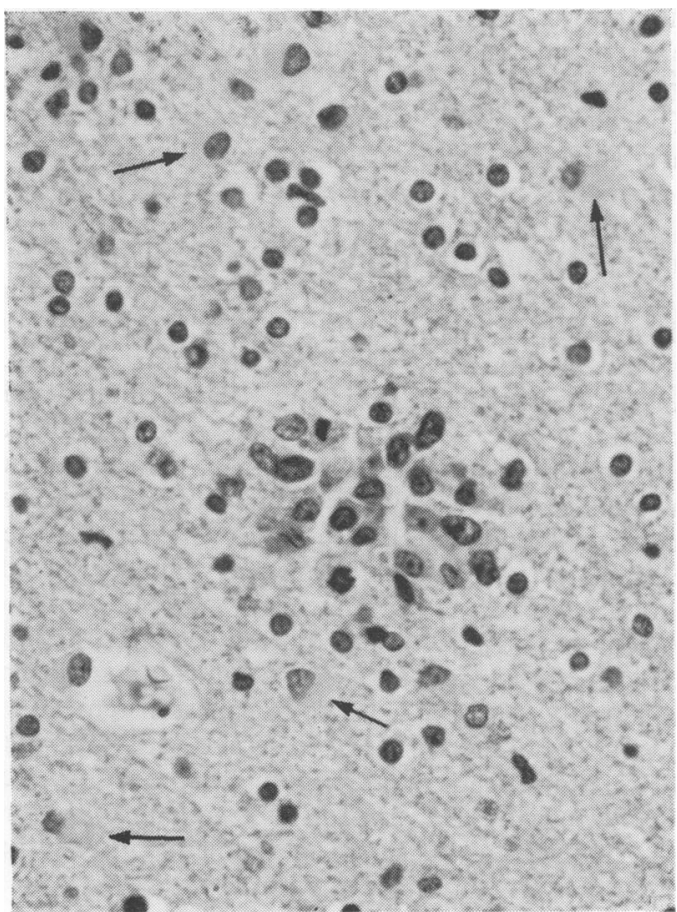

Fig. 6 Section of hemisphere white matter of the brain shown in Figure 5. There is a cluster of glial cells, one of which is in mitosis. Many astrocytes (arrows) have enlarged nuclei and swollen cytoplasm, evidence of degeneration in the white matter.

Haematoxylin and eosin $\times 320$.

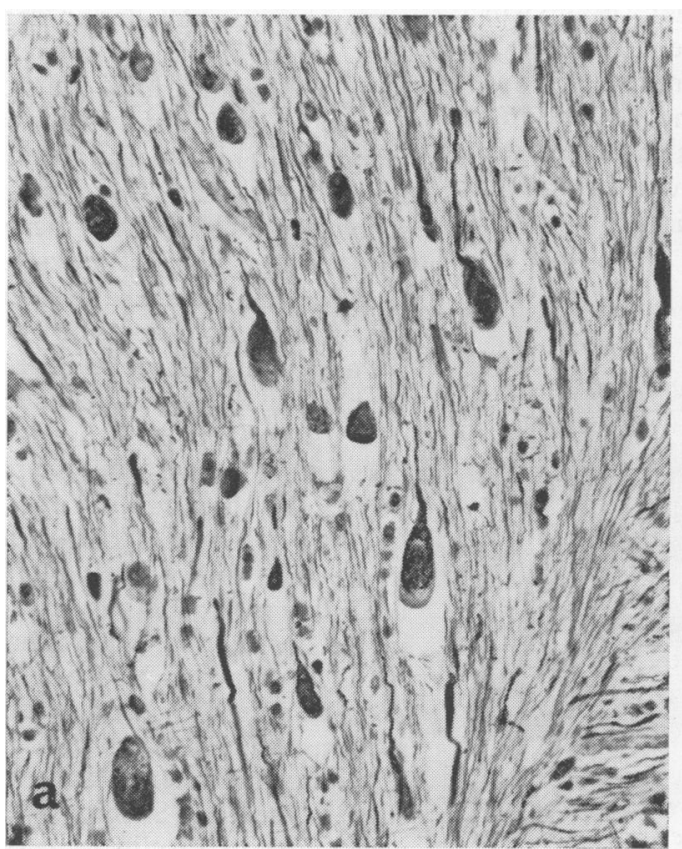

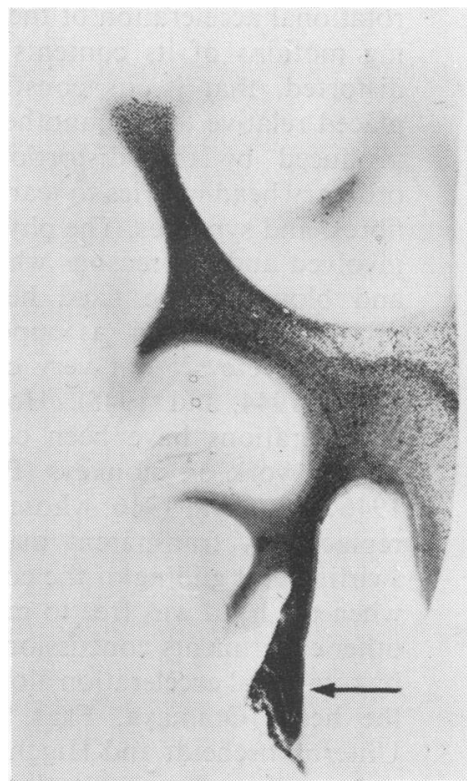

Fig. 7 Section from cerebrum showing extensive myelin degeneration in white matter and corpus callosum (arrow). Myelin breakdown products show as black dots (fat granule cells). From a boy aged 17 years who fell from a height and survived for one year in a state of 'akinetic mutism'. White matter and cortex were normal macroscopically. Marchi $\times 1 \cdot 3$.

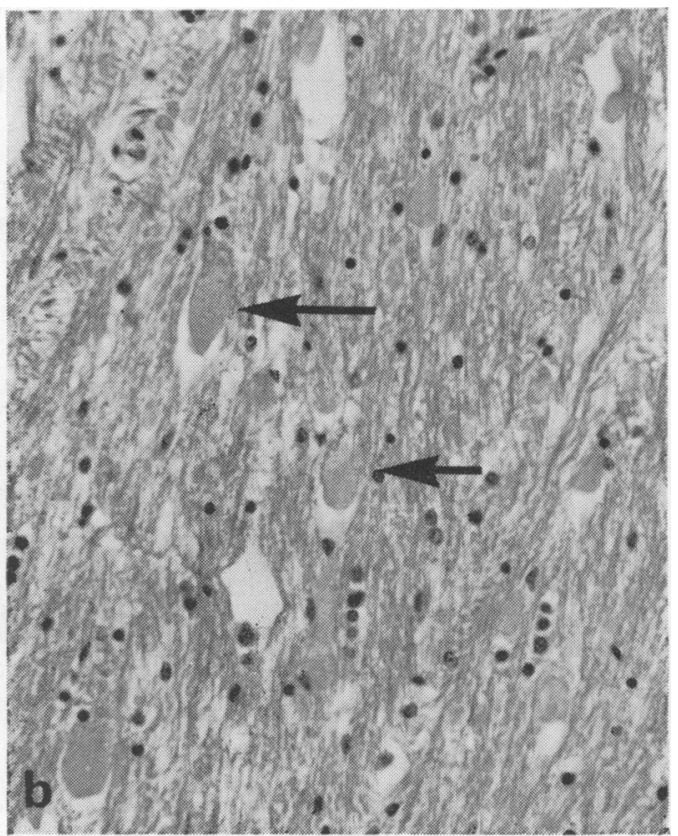

Fig. 8 From a woman aged 35 years who died 11 days after a road accident without having recovered consciousness. Section through internal capsule. (a) Palmgren silver impregnation. There are many argyrophilic swellings (retraction balls), some clearly at the ends of ruptured nerve fibres. (b) Haematoxylin and eosin. Retraction balls are present (arrows) but are less conspicuous than in $\mathrm{a} . \times 225$. 
rotational acceleration of the skull and the swirling motions of its contents the brain becomes distorted, that is, its constituents become displaced relative to one another. The shear strains produced by this distortion are sufficient in ordinary head injuries to tear blood vessels, nerve fibres, and synapses. The physics of the processes involved and the reasons why linear acceleration and blows to the fixed head are unlikely to produce generalized, as opposed to local, brain damage were set out very clearly by Holbourn (1943, 1944, and 1945). Holbourn's theoretical considerations have been confirmed by experimental work on monkeys (Pudenz and Shelden, 1946; Ommaya, 1966) whose skull caps had been replaced by transparent material. Considerable swirling and gliding of the convolutions was seen when the head was free to move after a blow. In other experiments concussion has been produced by rotational acceleration alone without impact to the head (Ommaya, Faas, and Yarnell, 1968; Unterharnscheidt and Higgins, 1969). Significant rotational acceleration or deceleration of the head occurs in a large proportion of human head injuries.

\section{Tearing of Nerve Fibres}

There is now good clinical and pathological evidence that nerve fibres can be torn in the brain at the time of the accident (Strich, 1956 and 1961). This type of brain damage cannot be seen with the naked eye even when severe. In many brains which macroscopically show a few haemorrhages only widespread damage to nerve fibres will be found microscopically (Figs. 5, 6, 7, and 8). The histological changes are the same as those following interruption of axons from any cause (Wallerian degeneration). When an axon is cut a bead of

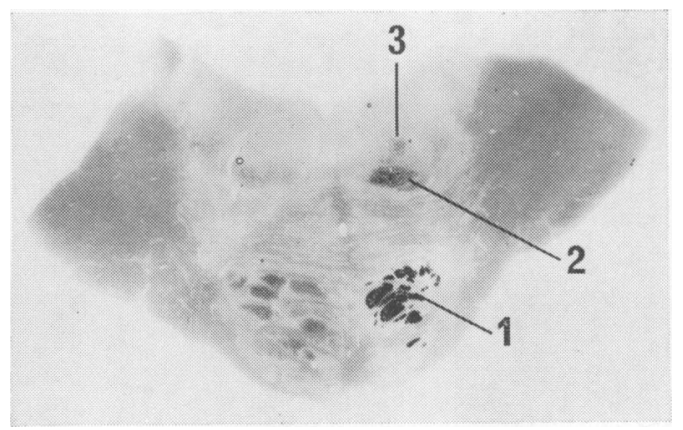

Fig. 9 Section of pons showing asymmetrical tract degeneration. There was severe nerve fibre degeneration in both hemispheres. From a boy aged 18 involved in a motorcycle accident. Became decerebrate and extremely demented, survival 13 months. 1 , pyramidal tract; 2, medial lemniscus; 3 , central tegmental tract. Marchi $\times 1 \cdot 3$. eosiniphilic and argyrophilic axoplasm calle a retraction ball or bulb (Fig. 8) forms at both ends within hours (Cajal, 1928). The portiom of the axon severed from the cell body beco irregular and fragmented and is resorbed in a few weeks. The retraction ball at the proximal ond remains visible for months. Retraction ballsodo not invariably form. They are often absent unfer cortical contusions and at the edge of haenowrhages, for example. Retraction balls are common in cases of head injury (Nevin, 1967; Peerless and Rewcastle, 1967). Their distribution depends 9 on the mechanics of the injury, and factors suchPas the direction of the shear strains relative to fibre direction are probably important. Thus it is fownd that bundles of nerve fibres running in one direction are damaged while nearby bungles running in a different direction may be spared. Degeneration is often strikingly asymmetrical, certain anatomical tracts in one hemisphere or-on one side of the brainstem (Fig. 9) being apparemily selectively involved. Good places to look for retraction balls are the corpus callosum (even when there is no naked-eye lesion), the parasagidfal areas of the hemispheres, the internal capsu隹s, and the pons.

\section{Wallerian Degeneration}

When a severed axon degenerates, its mye्युin sheath also undergoes Wallerian degeneration oln the peripheral nervous system this processonis completed in two or three weeks but in the central nervous system Wallerian degeneration is a vêry slow affair (Daniel and Strich, 1969, light miçoscopy; Bignami and Ralston, 1969, election microscopy). The early stages are quite difficult to recognize in histological sections, though degengerating tracts may look strikingly white macisoscopically. Under the microscope the affected white matter or tract looks 'untidy'. The myedin sheaths are distended and later collapsed and they are broken into spheres or sausages. The nuclepof the astrocytes enlarge and their cytoplasm become visible (Fig. 6); pyknotic nuclei and glial cells whth oddly shaped nuclei can also be seen. Microg cells (macrophages) are scanty in normal white matter and their number does not increase durifg the first few weeks of Wallerian degeneratidh. There is at first no loss of myelin and stainable breakdown products do not appear for several weeks. After this, macrophages full of mye्fin breakdown products (cholesterol esters) becoffine prominent and the degeneration is easily seentin sections stained with the Sudan dyes, Oil-redळ, or with osmium tetroxide (Figs. 7 and 9) as in The $^{2}$ Marchi method (Strich, 1968). After some eight weeks loss of myelin is recognizable in para in sections. The pattern of degeneration does not now reflect the pattern of the original damage. The whole length of the disconnected portion of the nerve fibre degenerates, the site or sites of ingr- 
ruption cannot usually be identified and degeneration of short fibres will be inconspicuous, whereas that of long fibres will be obvious.

\section{Microglial Reaction}

Recently clusters of microgial cells have been described scattered about in the brains of patients with head injuries surviving for more than 18 hours (Oppenheimer, 1968). These cells are probably reacting to minute tissue tears and were found in about two-thirds of the 59 cases examined. In the early stages these microglial cells are most readily seen in silver-impregnated sections (see Oppenheimer, 1968 for Weil-Davenport's modified method, frozen sections; Gallyas 1963, paraffin sections). After three or four weeks small collections of glial cells are characteristically seen in routine paraffin sections of the white matter (Fig. 6) from cases with massive tearing of nerve fibres.

\section{Concussion}

Concussion is supposed to be a completely reversible state. This does not exclude the occurrence of small, irreversible lesions from which clinical recovery may be complete. It is of great interest that clusters of microglial cells and retraction balls have been described in the brainstem and hemispheres in cases of concussion (Oppenheimer, 1968), that is, in patients who were briefly unconscious after a head injury, recovered, and died of other causes later. There is also the possibility of reversible lesions, for instance due to stretching rather than tearing of nerve fibres. Dislodging of synapses or displacement of cell organelles may also occur but such changes are unlikely ever to be seen in human necropsy material. The localization of visible lesions in human concussion has not been mapped out in detail. The brainstem is usually regarded as the important site, but the retrograde and posttraumatic amnesias and the confusion which are so prominent in concussion clinically suggest a more widespread cerebral dysfunction. The pathology of the postconcussion syndrome has not been investigated but it would be worth while to look for retraction balls and clusters of microglial cells should such a patient die within a few weeks of a minor head injury.

\section{References}

Adams, J. H., Brierley, J. B., Connor, R. C. R., and Treip, C. S. (1966). The effects of systemic hypotension upon the human brain. Clinical and neuropathological observations in 11 cases. Brain, 89, 235-268.

Bignami, A., and Ralston, J. H. (1969). The cellular reaction to Wallerian degeneration in the central nervous system of the cat. Brain Res., 13, 444-461.

Cajal, R. y. (1928) In Degeneration and Regeneration of the Nervous System, edited and translated by R. M. May, vol. II. pp. 484-516. Hafner, New York. Reprinted 1956.

Daniel, P. M., and Strich, S. J. (1969). Histological observations on Wallerian degeneration in the spinal cord of the baboon, Papio papio. Acta neuropath. (Berl.), 12, 314-328.

Gallyas, F. (1963). Silver impregnation method for microglia. Acta neuropath. (Berl.), 3, 206-209

Goldsmith, W. (1966). In Head Injury, edited by W. F. Caveness and A. E. Walker, pp. 514-516. Lippincott, Philadelphia and Toronto.

Gross, A. G. (1958). A new theory on the dynamics of brain concussion and brain injury. J. Neurosurg., 15, 548-561.

Holbourn, A. H. S. (1943) Mechanics of head injuries. Lancet, 2. 438-441.

Holbourn, A. H. S. (1944). The mechanics of trauma with special reference to herniation of cerebral tissue. J. Neurosurg., 1 190-200.

Holbourn, A. H. S. (1945). The mechanics of brain injuries. Brit. med. Bull., 3, 147-149.

Klatzo, I. (1967). Neuropathological aspects of brain edema. $J$. Neuropath. exp. Neurol., 26, 1-14.

Klatzo, I., Piraux, A., and Laskowski, E. J. (1958). The relationship between edema, blood-brain-barrier and tissue elements in a local brain injury. J. Neuropath. exp. Neurol., $17,548-564$.

Krauland, W. (1950). Über Hirnschäden durch stumpfe Gewalt Dtsch. Z. Nervenheilk., 163, 265-328.

Lindenberg, R.. Fisher, R. S., Durlacher, S. H., Lovitt, W. V., Jr., and Freytag, E. (1955). Lesions of the corpus callosum following blunt mechanical trauma to the head. Amer. $J$. Path., 31, 297-317.

Mayer, E. T. (1967) Zentrale Hirnschäden nach Einwirkung stumpfer Gewalt auf den Schädel. Hirnstammläsionen. Arch. Psychiat. Nervenkr., 210, 238-262.

Nevin, N. C. (1967). Neuropathological changes in the white matter following head injury. J. Neuropath. exp. Neurol., 26, 77-84.

Ommaya, A. K. (1966). Trauma to the nervous system. Ann. roy. Coll. Surg. Engl., 39, 317-347.

Ommaya, A. K., Faas, F., and Yarnell, P. (1968). Whiplash injury and brain damage. J. Amer. med. Ass., 204, 285-289.

Oppenheimer. D. R. (1968). Microscopic lesions in the brain following head injury. J. Neurol. Neurosurg. Psychiat., i31, 299-306.

Peerless, S. J., and Rewcastle, N. B. (1967). Shear injuries of the brain. Canad. med. Ass. J., 96, 577-582.

Pudenz, R. H., and Shelden, C. H. (1946). The Lucite calvariumA method for direct observation of the brain. II Cranial trauma and brain movement. J. Neurosurg., 3, 487-505.

Sellier, K., and Unterharnscheidt. F. (1963). Mechanik und Pathomorphologie der Hirnschäden nach stumpfer Gewalteinwirkung auf den Schädel. Hefte Unfallheilk., 76, $1-140$.

Strich, S. J. (1956). Diffuse degeneration of the cerebral white matter in severe dementia foliowing head injury. J. Neurol. Neurosurg. Psychiat., 19, 163-185.

Strich, S. J. (1961). Shearing of nerve fibres as a cause of brain damage due to head injury. Lancet, 2, 443-448.

Strich, S. J. (1968). Notes on the Marchi method for staining degenerating myelin in the peripheral and central nervous system, J. Neurol. Neurosurg. Psychiat., 31, 110-104.

Strich, S. J. (1969). The pathology of brain damage due to blunt head injury. In The Late Effects of Head Injury, edited by A. E. Walker, W. F. Caveness, and M. Critchley, pp. 501-524. Thomas, Springfield, Illinois.

Tomlinson, B. E. (1964). Pathology. In Acute Injuries of the Head, edited by G. F. Rowbotham, 4th ed., pp. 93-158. Livingstone, Edinburgh and London.

Welte, E. (1948). Uber die Zusammenhänge zwischen anatomischem Befund und klinischem Bild bei Rindenprellungsherden nach stumpfem Schädeltrauma. Arch. Psychiat. Nervenkr., 179, 243-315.

Unterharnscheidt, F., and Higgins, L. S. (1969). Traumatic lesions of brain and spinal cord due to nondeforming angular acceleration of the head. Tex. Rep. Biol. Med., 27, 127-166. 